\title{
Expression of a cAMP receptor gene of Dictyostelium and evidence for a multigene family
}

\author{
Charles L. Saxe III, ${ }^{1,3}$ Ronald L. Johnson, ${ }^{2}$ Peter N. Devreotes, ${ }^{2}$ and Alan R. Kimmel ${ }^{1}$ \\ ${ }^{1}$ Laboratory of Cellular and Developmental Biology, NIDDK, National Institutes of Health, Bethesda, Maryland 20892 USA; \\ ${ }^{2}$ Department of Biological Chemistry, Johns Hopkins University, School of Medicine, Baltimore, Maryland 21205 USA
}

\begin{abstract}
We have previously reported the cloning of cDNAs for a Dictyostelium cell-surface cAMP receptor that is a member of the family of G-protein-linked receptors. Here, we report the organization and the developmental expression of this cAMP receptor gene, designated CAR1. CAR1 is a single copy gene that contains two intervening sequences. CAR1 mRNA levels are low in growing cells, rise to peak expression at 5-10 hr of development when the cAMP signaling system is maximally active, and decrease as development proceeds. At $5 \mathrm{hr}$ the predominant mRNA species is $\sim 1.9 \mathrm{~kb}$, by $10 \mathrm{hr}$ the mRNA is heterogeneous with sizes of $\sim 1.9-2.1 \mathrm{~kb}$, but during culmination only the $2.1 \mathrm{~kb}$ mRNA is detected. The variety of mRNA sizes results from differences in 5 -untranslated regions. Studies using developmental mutants with aberrant cAMP-signaling patterns indicate that pulsatile action of cAMP promotes maximal expression of CAR1 during early development. Low stringency hybridization of $C A R 1$ probes to genomic DNA detects additional, related sequences, suggesting that there are several genes that encode a family of structurally similar receptors. Multiple functions previously attributed to the cAMP receptor instead may be fulfilled by distinct receptor subtypes encoded by specific genes.
\end{abstract}

[Key Words: cAMP; receptors; gene expression; Dictyostelium]

Received July 18, 1990; revised version accepted October 30, 1990.

In Dictyostelium discoideum a receptor-mediated cellcell communication system is established upon nutrient deprivation, enabling cells to migrate, become cohesive, and coalese to form multicellular structures (Loomis 1982). A regulated developmental program results in the formation of the fully differentiated fruiting body. An essential feature of this program is the stimulation of G-protein-linked receptors, which bind extracellular cAMP (for review, see Firtel et al. 1989).

Central to the organization of early development is the oscillating waves of extracellular cAMP, which propogate outward from the middle of aggregation centers (Devreotes 1982). The cAMP serves as a chemoattractant and as a transmitter that activates adenylyl cyclase, guanylyl cyclase and, probably, phospholipase C (for review, see Janssens and Van Haastert 1987). The resulting increases in the intracellular messengers cAMP, $\mathrm{IP}_{3}$, cGMP, and $\mathrm{Ca}^{2++}$ and in secreted cAMP are transient as ligand-induced stimulation of receptors leads to desensitization (Dinauer et al. 1980; Van Haastert 1987). After extracellular cAMP is degraded by membrane-bound and secreted phosphodiesterases, receptors regain sensitivity and another wave of cAMP stimulation occurs (Devreotes 1982). The repetitive activation of receptors also leads to changes in the pattern of gene expression

${ }^{3}$ Present address: Department of Cell Biology, Emory Medical School, Atlanta, Georgia 30322 USA. during early developmental stages (Kimmel and Carlisle 1986; Kimmel and Saxe 1986; Kimmel 1987; Mann and Firtel 1987). However, later in development, when specific cell types are formed, there is a requirement for constant cAMP receptor stimulation (Schaap and van Driel 1985; Gomer et al. 1986; Haribabu and Dottin 1986; Oyama and Blumberg 1986; Kimmel 1987; Wang et al. 1988).

Cloned cDNAs for a cAMP receptor expressed during early development have been isolated (Klein et al. 1988). Its derived amino acid sequence suggests a protein structure that is topologically similar to other G-protein-coupled receptors, characterized by seven hydrophobic domains (Dohlman et al. 1987). Here, we report the genomic organization and developmental expression of this cAMP receptor gene, designated CAR1. We find evidence for a single copy of $C A R 1$ in the $D$. discoideum genome and a major accumulation of its mRNA when the cAMP signal-relay system is being assembled. Following the formation of multicellular structures, mRNA levels decline and mRNA size heterogeneity is detected. These sizes result from differences in the 5 '-untranslated region of the CAR1 mRNA. Maximal induction of $C A R 1$ expression requires a cAMP signal response coupled to an intracellular system that may be independent of adenylyl cyclase activation.

Finally, we report evidence for additional $D$. discoideum genes that are related to CAR1. The existence of 
these genes suggests the possibility that the multiple effects ascribed to extracellular cAMP may be mediated by a family of receptors with distinct effector targets.

\section{Results}

\section{Genomic organization of CAR1}

We used full-length and 3 '-specific cDNA probes to examine the genomic organization of CAR1 by DNA blot hybridization (Fig. 1A). Under relatively high-stringency

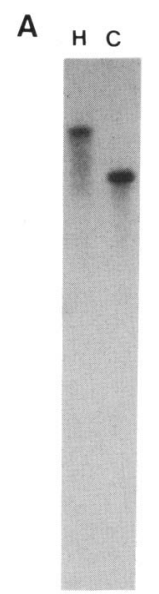

$\mathbf{F}$

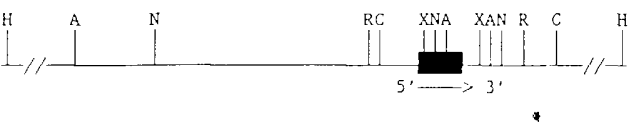

B

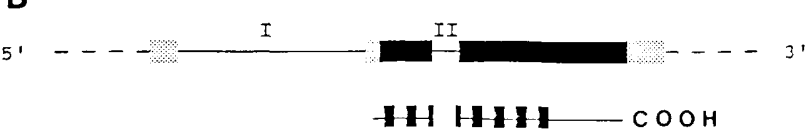

Figure 1. Genomic organization of the CAR1 locus of $D$. discoideum. (A) Genomic DNA was digested with HindIII $(\mathrm{H})$, ClaI $(\mathrm{C}), N d e \mathrm{I}(\mathrm{N})$, or AvaII (A) restriction enzymes, separated by gel electrophoresis, and blotted for hybridization with probes from CAR1 cDNAs. The full-length probe (F) encompassed the entire protein-coding region and the $3^{\prime}$ probe was derived from the terminal $564 \mathrm{bp}$. Hybridizations were performed at $37^{\circ} \mathrm{C}$. The diagram indicates positions in the genome of restriction enzyme sites relative to CAR 1 ( $\mathbf{\square})$. (R) EcoRI; $(\mathrm{X})$ $X b a I .(B)$ The diagram of the CAR1 gene indicates the relative positions of the $5^{\prime}$ - and $3^{\prime}$-untranslated regions (stippled box), the protein-coding regions (solid box), the introns (solid line), and untranscribed flanking sequences (dashed line) for CAR1 mRNAs expressed during early development. Below the diagram, the structural domains of the $C A R 1$ protein relative to the protein-coding region are indicated: extracellular and intracellular domains (solid line) and transmembrane domains (solid box). Intron I is located at nucleotide -38 relative to the AUG; intron II is at nucleotide +310 and interrupts sequences that encode transmembrane domain 3. ol igo A

ICTCTCTCTCTCTCTCIAATATCAAATCAAAACGATAAATCGAATAAATITAAG GTAATTAATATTATIAATAAAT

oligo B

AGATCAAAA …(1200nt) -... IITTCCTCTCTTTTCTTTTATTTTCAAATAATTATAGAACGCTA

AATITAAAAAAATAATTGTATTAATACAATAAAAAAAAAAAAAAAAAAAATTATTTAAAATACAAATCACATACATAAAC

IATCTAG AItITICACacatatatatatataAataaAaAaAtaAa ATG GGT CTT TTA Gat gGa

Figure 2. Sequence location of $C A R 1$ intron I. Partial genomic DNA sequence of the $5^{\prime}$-coding region of CAR1. Derived amino acids beginning with the AUG initiation codon are indicated. The intron sequence is bold and underlined. Its position was determined by comparison with CAR1 cDNA sequences (Klein et al. 1988). Its length was determined by PCR amplification of genomic DNA using the indicated oligonucleotides $\mathrm{A}$ and $\mathrm{B}$ (see Fig. 3).

conditions, simple hybridization patterns were observed. Enzymes that do not cleave the cDNA (HindIII and ClaI) generate single bands with either probe. Enzymes that cleave the cDNA once (NdeI or AvaII) yield two bands that hybridize to the full-length cDNA probe and only one that hybridizes to the 3 '-specific probe. We have mapped $>30 \mathrm{~kb}$ of sequences surrounding CAR1 and have not observed any restriction fragment-length heterogeneity within a strain. These results are consistent with the presence of a single copy of this gene in $D$. discoideum, although we cannot exclude the possibility of a large duplication of this region in the genome. The derived genomic restriction map is presented in Figure $1 \mathrm{~A}$.

We have also compared the restriction maps and DNA sequences of $C A R 1$ cDNAs from early in development with isolated genomic clones. The cDNA and genomic sequences were colinear except for two introns that are $\mathrm{A}+\mathrm{T}$-rich and are flanked by consensus splice sites (Kimmel and Firtel 1980). The first intron lies 38 bp upstream of the start codon (Fig. 2). The approximate length (1300 bp) and position of intron I was confirmed by polymerase chain reaction (PCR) amplification of genomic and cloned CAR1 DNA using oligonucleotides that flank intron sequences (Fig. 3). Figure 4 shows the 142-bp sequence of the second intron. It lies within the putative third transmembrane domain of the proteincoding region and was localized precisely by comparison with cDNA sequences (Klein et al. 1988). Figure 1B is a diagram of the general structure for the CAR1 transcript during early development and indicates the relative location of the encoded $C A R 1$ protein domains.

\section{Multiple receptor genes}

To determine whether there were other Dictyostelium genes related to $C A R 1$, we performed hybridizations at reduced stringency conditions (Fig. 5). CAR1 probes hybridize strongly to $C A R 1$ receptor-specific fragments (cf. 

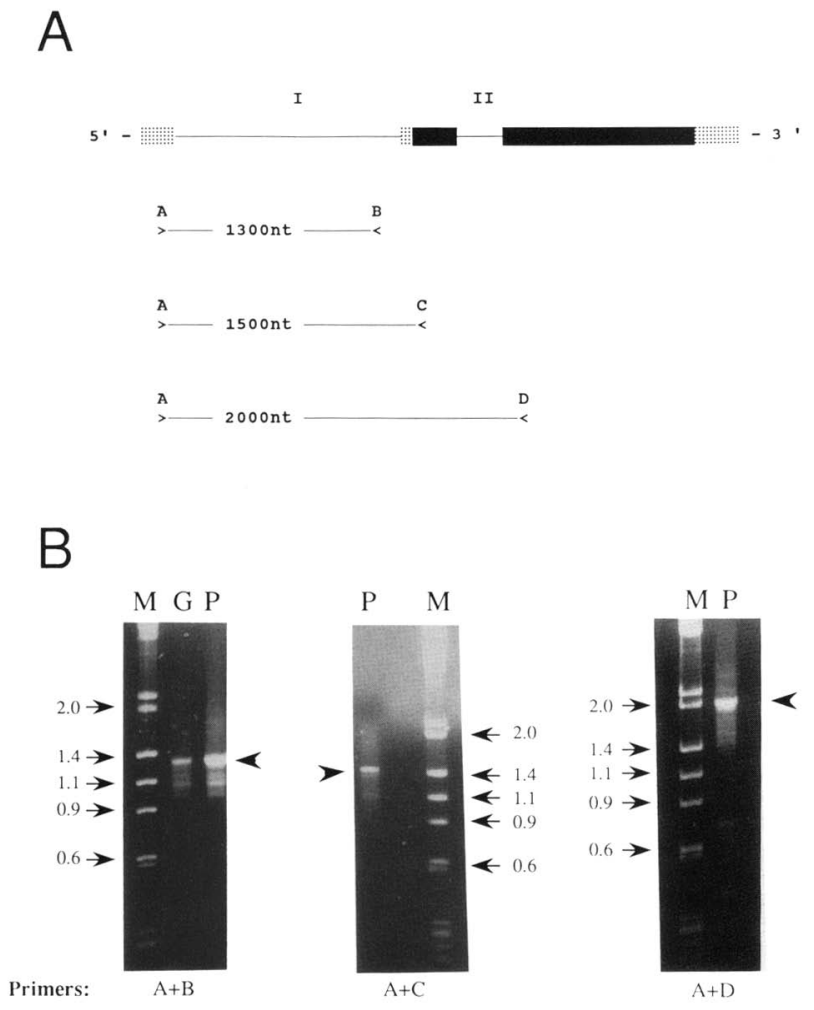

Figure 3. Mapping the CAR1 intron I by PCR. $(A \mid$ Diagram of the CAR1 gene structure indicating relative positions of introns $\mathrm{I}$ and II and of PCR oligonucleotides A-D. Exact positions of oligonucleotides A and B are shown in Fig. 2. Oligonucleotide A is located in the $5^{\prime}$-untranslated region upstream of intron $I$; oligonucleotide B is located within the intron, near the 3 '-splice junction. Oligonucleotides $\mathrm{C}$ and $\mathrm{D}$ are located in the proteincoding region; oligonucleotide $C$ starts at position +42 (relative to the AUG) and oligonucleotide $\mathrm{D}$ is at position +538 . Approximate distances between the oligonucleotides are also indicated (see $B$ ). (Solid box) Protein-coding region; (stippled box) untranslated region; (solid line) intron. (B) Total $D$. discoideum genomic $(\mathrm{G})$ or cloned CAR1 plasmid $(\mathrm{P})$ DNA was amplified by the PCR technique (see Materials and methods). As indicated, oligonucleotide pairs were $\mathrm{A}+\mathrm{B}, \mathrm{A}+\mathrm{C}$, or $\mathrm{A}+\mathrm{D}$ (see $A$ ). PCR products were analyzed by gel electrophoresis. The predominant band in each amplification is indicated by an arrowhead. Size markers $(M$, in $k b)$ of $\lambda$ DNA digested with restriction enzyme HindIII and $\phi \times 174$ replicative form DNA digested with HaeIII.

with Fig. 1A) but also weakly to additional bands, suggesting that there are several genes related to CAR1 in the genome. To determine the regions of sequence similarity among them and to identify gene-specific sequences, probes of similar size but from different regions of CAR1 were also used for blot hybridizations. The transmembrane (TM) probe (see Fig. 6A) contains a 211bp sequence corresponding to a region encoding transmembrane domains 6 and 7 and extracellular loop 3 of the CAR1 receptor protein (Klein et al. 1988). The carboxy-terminal (CT) probe (see Fig. 6A) contains the $3^{\prime}$ most $271 \mathrm{bp}$ of the protein-coding region. As seen in Figure $6 \mathrm{~B}$, under relaxed hybridization conditions, the

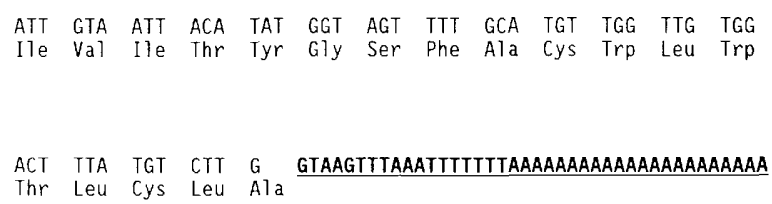

Figure 4. Location and sequence of the CAR1 intron II. Genomic DNA sequence within the protein-coding region of $C A R 1$. Derived amino acids are indicated. The intron sequence is bold and underlined and interrupts codon 103. Its position was determined by comparison with CAR1 cDNA sequences (Klein et al. 1988).

TM probe recognized other bands in addition to those of $C A R 1$, whereas the CT probe hybridizes specifically to $C A R 1$ fragments. Probes from regions that span other transmembrane domains yield similar low-stringency hybridization patterns (data not shown). The cross-hybridizing fragments would suggest the presence of a family of genes that encode proteins similar to CAR1.

\section{Expression of CAR1 during development}

We examined the expression of CAR1 during the major stages of the $D$. discoideum developmental cycle. To avoid potential interference by cross hybridization with

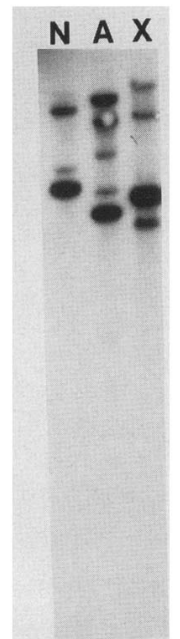

Figure 5. Cross hybridization of CAR1 to related genomic sequences. Genomic DNA was digested with NdeI (N), AvaII (A), or $\mathrm{XbaI}(\mathrm{X})$ restriction enzymes, separated by gel electrophoresis, and blotted for hybridization to a full-length probe from $C A R 1 \mathrm{cDNA}$ at reduced stringency $\left(22^{\circ} \mathrm{C}\right)$. 
A
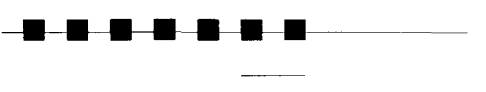

receptor protein

Transmentrane probe (TM)

Carboxyl terminal probe (CT)

B

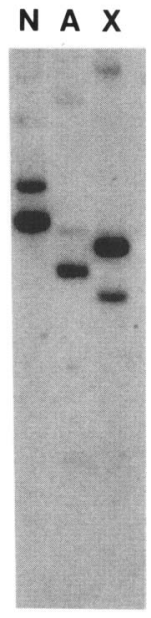

T M
N A X

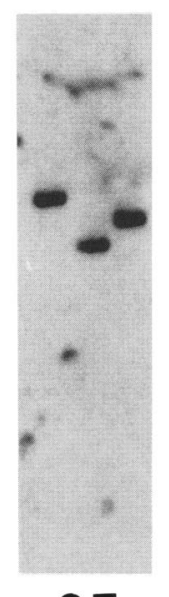

C T
Figure 6. Mapping of cross-hybridizing sequences with CAR1. (A) Diagram of CAR1 protein, indicating transmembrane domains (solid box) and intracellular and extracellular domains (solid lines). The transmembrane (TM) domain probe contains sequences corresponding to TM domains 6 and 7; the carboxyterminal (CT) probe contains sequences corresponding to the CT domain. (B) Dictyostelium DNA was digested with NdeI (N), AvaII $\langle\mathrm{A}|$, or $\mathrm{XbaI}(\mathrm{X})$ restriction enzymes, separated by gel electrophoresis, and blotted for hybridization to TM or CT at reduced stringency $\left(22^{\circ} \mathrm{C}\right)$.

transcripts from the additional receptor genes we used the CT probe, which even under relaxed hybridization conditions only detects CAR1 on DNA blots (see Fig. 6); because DNA-DNA duplexes are less stable than equivalent RNA-DNA duplexes, we adjusted the hybridization conditions to ensure the equivalent specificity of the carboxy-terminal-CAR1 probe on RNA blot hybridizations (Wahl et al. 1987).

In growing cells, the levels of CAR1 mRNA were low (Fig. 7A). By $5 \mathrm{hr}$, the stage of development when the cAMP-signaling system is established, a single major species of $\sim 1.9 \mathrm{~kb}$ has accumulated. While mRNA levels remained elevated during aggregation $(10 \mathrm{hr})$, the size became heterogeneous $(\sim 1.9-2.1 \mathrm{~kb})$, and as levels decreased during the latter stages of development $(15$ and $20 \mathrm{hr}$, the $2.1-\mathrm{kb}$ species of CAR1 mRNA predominated. A larger, less abundant RNA species may also be detected. Identical results were obtained using a fulllength CAR1 cDNA probe (Fig. 7B).

To determine whether cAMP signaling is involved in the regulation of CAR1 expression, we compared control $(A x-3)$ cells with two developmental mutants, frigid A and agip 53, which are unable to establish or respond normally to a cAMP signal. The frigid A strain HC-33 fails to undergo chemotaxis or to synthesize cAMP or cGMP in response to exogenously added cAMP /Coukell et al. 1983; Snaar-Jagalska et al. 1988; Kumagai et al. 1989). Moreover, HC-33 is unable to complete development in the presence of strains that produce normal cAMP signals. Agip 53 is also unable to produce cAMP signals or aggregate by itself; however, it can be induced to acquire chemotactic ability and complete development in the presence of strains that produce a cAMP signal or by supplying exogenous cAMP (Darmon et al. 1977; Juliani and Klein 1978; Wurster and Bumann 1981). These exogenous cAMP signals trigger increases in cGMP but not in cAMP within agip 53 cells.

Ax-3 (control cells), HC-33, and agip 53 were grown to early $\log$ phase, washed from nutrients, and shaken in differentiation buffer. Separate cultures of each strain received no immediate treatment $|-|$ or $25 \mathrm{nM}$ pulses of cAMP $(\mathrm{P})$ to mimic normal cAMP signaling. Each culture was split after $10 \mathrm{hr}$. Identical cultures then received no treatment $(20)$ or cAMP to $1 \mathrm{~mm}(20+)$ to promote later stages of differentiation.

In suspension cultures of Ax-3 cells, CAR1 mRNA accumulates during early differentiation similar to development on a solid substrate and then declines during later stages (Fig. 8A). Providing Ax-3 cells with exogenous pulses of cAMP accelerates slightly the appearance
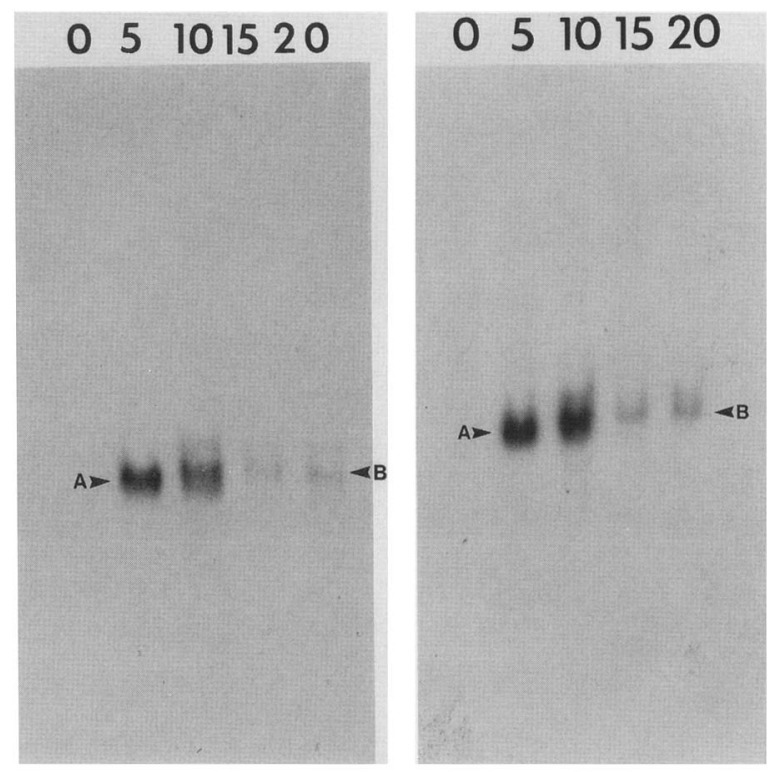

Figure 7. Developmental expression of CAR1 mRNA. Wildtype cells growing on bacteria were harvested in logarithmic phase, washed, plated on filter pads, and allowed to synchronously develop. At 5-hr intervals cells were collected, and poly $(A)^{+}$RNA was isolated. The RNAs were separated by size on denaturing gels and blotted for hybridization. (Left) Hybridization with the CAR1-specific, carboxy-terminal probe (see Fig. $3 \mathrm{~A})$ at high stringency $\left(37^{\circ} \mathrm{C}\right)$. These conditions are $15^{\circ} \mathrm{C}$ higher than the relaxed conditions used for the DNA blots in Figs. 2 and 3. (Arrowhead A) 1.9-kb mRNA; (arrowhead B) 2.1kb mRNA. (Right) Hybridization with full-length CAR1 cDNA probe (see Fig. 1) at high stringency $\left(37^{\circ} \mathrm{C}\right.$ ). (Arrowhead $A$ ) 1.9kb mRNA; (arrowhead $B$ ) 2.1-kb mRNA. 


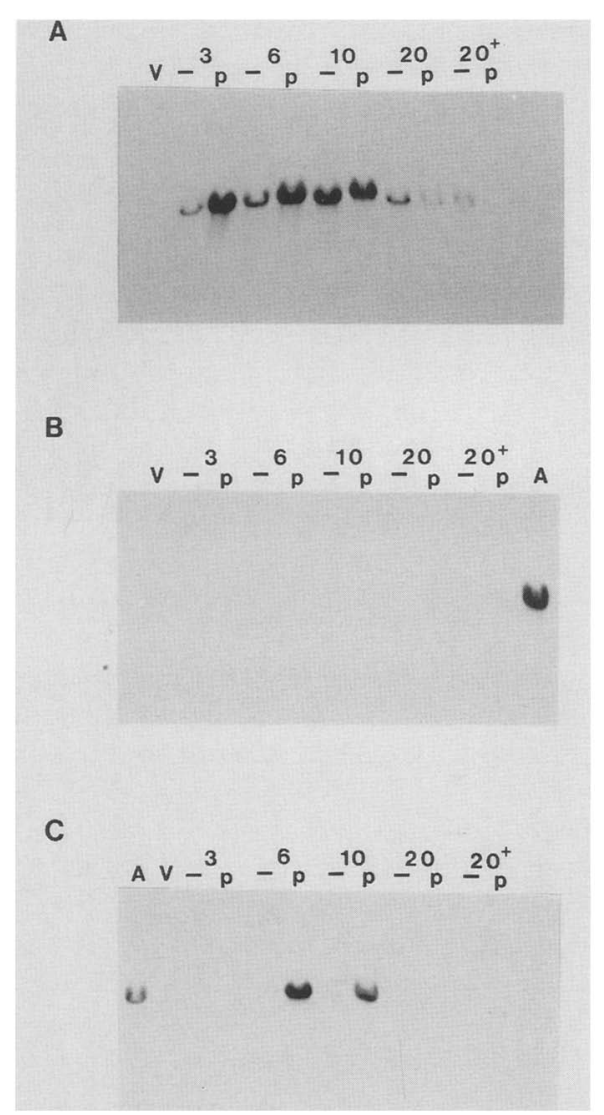

Figure 8. Expression of $C A R 1$ mRNA in Ax-3, HC-33, or agip 53. Different strains of $D$. discoideum were grown to early $\log$ phase, washed, and shaken in differentiation buffer. Separate cultures of each strain received no treatment $(-)$ or $25 \mathrm{~nm}$ pulses of cAMP (P) to mimic normal cAMP signaling. After 10-hr cultures were split, each receiving either no treatment (lane 20) or cAMP to $1 \mathrm{mM}$ (lane $20+$ ) to promote later stages of differentiation. RNA was isolated at various times, separated, and blotted for hybridization with CAR1-specific probes. (V) RNA from vegetatively growing cells; (A) RNA from Ax-3 cells differentiated in liquid culture. $(A) \mathrm{Ax}-3$ (control) cells; $(B)$ HC-33 (frigid A) strain; $(C)$ agip 53 cells.

of CAR1 mRNA. The frigid A mutant cells are unable to accumulate CAR1 mRNA above the low level detected in growing cells whether or not the cells are presented with exogenous cAMP either intermittantly or continuously (Fig. 8B). Although untreated agip 53 cells are unable to accumulate CAR1 mRNA, repeated stimulation with exogenous CAMP promotes its accumulation with normal developmental kinetics (Fig. 8C). Thus, it appears that oscillatory cAMP signaling is required for the maximal induction of CAR1 mRNA expression. However, because the expression of CAR1 is stimulated in agip 53 cells, CAR 1 induction appears to be independent of periodic increases in intracellular cAMP and may depend on other intracellular messengers.

\section{CAR1 $m R N A$ length heterogeneity}

Data presented in Figure 7 indicate that multiple size forms of CAR1 mRNA are expressed during develop- ment. RNase $\mathrm{H}$ cleavage experiments were used to localize the length heterogeneity within the transcripts (see Fig. 9). RNAs were hybridized with CAR1-specific oligonucleotides, and the duplexes were digested with RNase $\mathrm{H}$, which only cleaves RNA-DNA hybrids (Berger 1987). Products were separated on denaturing gels and hybridized with $5^{\prime}$ - or $3^{\prime}$-specific probes /see Figs. 9 and 10 ). Conditions of hybridization assured that only CAR1 mRNA sequences would be detected.

Fragments of CAR1 mRNA 3' of nucleotide +538 (relative to the AUG start codon) were similar in length, whereas fragments $5^{\prime}$ of nucleotide +935 differed during development (Fig. 10). At $5 \mathrm{hr}$ the $5^{\prime}$ fragments appeared as a closely spaced doublet, whereas at $10 \mathrm{hr}$ an additional, larger CAR1 band was detected. A spectrum of $5^{\prime}$ bands was also observed in the RNA isolated from Ax-3 cells differentiated in suspension culture for $8 \mathrm{hr}$. At 15 hr the larger sized $5^{\prime}$ fragment was predominant. An additional, even larger band may be present that may derive from the large, rare mRNA detected during late development (see Fig. 7). The differences in 5 ' fragment sizes account largely for the size heterogeneity observed on the developmental RNA blot (see Fig. 7), although slight differences in poly(A) length cannot be excluded by these data.

Because the CAR1 mRNA size heterogeneity must lie $5^{\prime}$ of nucleotide +538 , we used oligonucleotides to amplify the CAR1 mRNA from nucleotide 1 to nucleotide +538 using reverse transcriptase coupled to PCR. We found no size differences at any of the developmental stages examined (Fig. 11). Thus, the CAR1 mRNA size heterogeneity must derive from differences in their $5^{\prime}$ untranslated regions. All of the CAR1 mRNA forms would potentially encode identical proteins.

Knowing the lengths of the $5^{\prime}$ - and $3^{\prime}-\mathrm{RNase} \mathrm{H}$ fragments and the relative positions of the oligonucleotides within the protein-coding region, we determined the lengths of the $5^{\prime}$ - and $3^{\prime}$-untranslated regions of the CAR1 mRNAs during the different developmental stages. The RNAs present throughout development contain 3 '-untranslated regions of $\sim 450$ nucleotides. At $5 \mathrm{hr}$

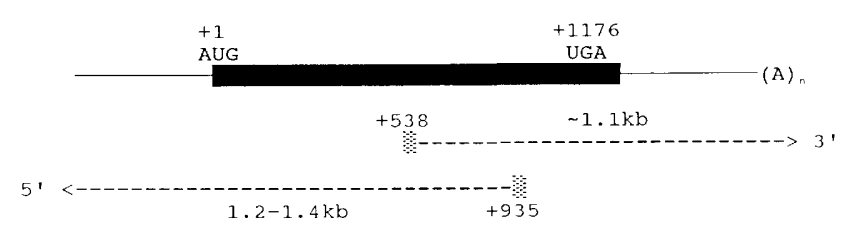

Figure 9. Diagram for mapping RNase $\mathrm{H}$ cleavage sites on CAR1 mRNA. CAR1 mRNA with its $3^{\prime}$ poly(A) tail is hybridized with oligonucleotides that are specific for $C A R 1$. The protein-coding (solid bar) and untranslated (solid line) regions of the CAR1 mRNA are indicated as are the nucleotide positions of the AUG start codon, the UAG stop codon, and the oligonucleotides (stippled area). Hybrid molecules are digested with $\mathrm{RNase} \mathrm{H}$ to generate fragments that lie $3^{\prime}$ or $5^{\prime}$ to the RNase $\mathrm{H}$ cleavage sites at positions +538 and +935 , respectively. These fragments were separated by size, blotted, and hybridized to probes specific for the $3^{\prime}$ or $5^{\prime}$ ends of the CAR1 mRNA molecule. Heterogeneity in the cleavage products would indicate heterogeneity at the $3^{\prime}$ or $5^{\prime}$ end of the CAR 1 mRNA molecule. 

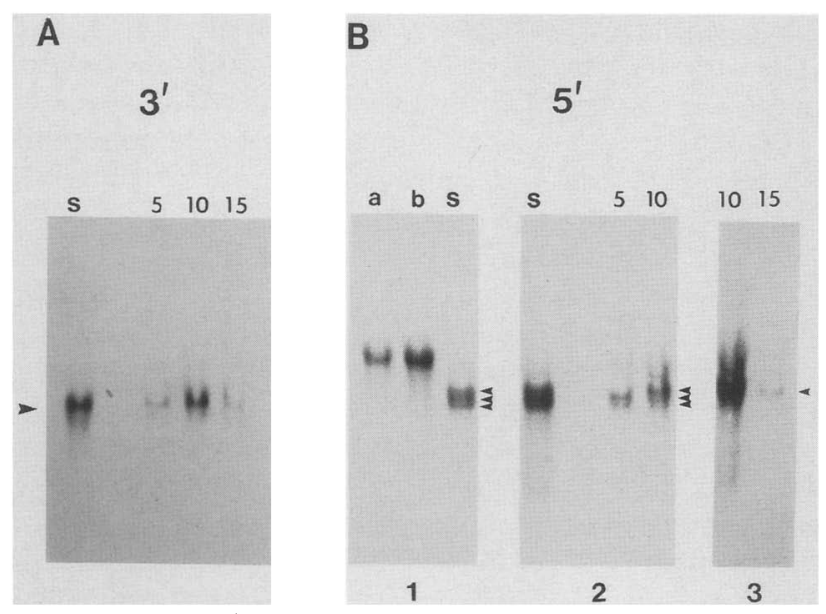

Figure 10. Mapping of size heterogeneity on CAR1 mRNA by RNase H. (A) ( $3^{\prime}$ mapping) RNAs from cells differentiated in suspension culture(s) or developed on filters for 5,10 , and $15 \mathrm{hr}$ were analyzed as described in Fig. 6. Fragments that lie 3 ' to the RNase H cleavage site at position +538 (see Fig. 9) were detected by autoradiography of the blot hybridizations. The common-size band hybridizing in all lanes is indicated by the arrowhead. (B) (5' mapping) RNAs from cells differentiated in suspension culture(s) or developed on filters for 5,10 , and $15 \mathrm{hr}$ were analyzed as described in Fig. 9. Undigested RNAs in the control lanes were processed without RNase $\mathrm{H}$ (a) or without the oligonucleotide (b). Fragments that lie $5^{\prime}$ to the RNase $\mathrm{H}$ cleavage site at position +935 (see Fig. 9) were detected by autoradiography of the blot hybridizations. Overlapping portions of three exposures of the identical autoradiograph are presented: Exposure 1, $4 \mathrm{hr}$; exposure 2, $20 \mathrm{hr}$; exposure 3, $72 \mathrm{hr}$. Arrowheads indicate the multiple $5^{\prime}$ bands.

in development the $5^{\prime}$-untranslated regions are $\sim 250-300$ nucleotides, whereas at $10 \mathrm{hr}$ an additional size form of $\sim 450$ nucleotides is observed that persists through later stages.

\section{Discussion}

Extracellular cAMP plays a critical role in the developmental program of Dictyostelium (for review, see Devreotes 1989/. Because its effects appear to be mediated through cell-surface cAMP receptors, we have focused our attention on these molecules. Previously isolated cDNAs for a cell-surface cAMP receptor, CAR1 (Klein et al. 1988) were used to analyze the genomic organization of this receptor gene. CAR1 is encoded by a single-copy gene. CAR1 mRNA levels are low in growing cells and accumulate rapidly during the first several hours of development, as do $C A R 1$ protein and surface cAMP-binding sites. Levels of all of these decline after the multicellular structure forms (Klein et al. 1987). Taken together, these data are most consistent with a transcriptional mode of regulation for CAR1 expression during development.

The cAMP receptor appears to be involved in the positive regulation of its own expression. As cAMP stimulates the few receptors on the surface of growing cells, intracellular signaling pathways are activated and re- ceptor expression increases. This cascade of events promotes the maximal levels of CAR1 RNA observed during early development. Cells that do not exhibit a functional signaling system (as exhibited by certain frigid A mutants) cannot maximally activate $C A R 1 \mathrm{ex}-$ pression. Cells blocked in cAMP-regulated adenylyl cyclase activation are able to accumulate CAR1 mRNA and CAMP-binding sites if presented with repeated cAMP stimuli. Because these cells are not blocked in guanylyl cyclase and, presumably, phospholipase $\mathrm{C}$ activation, it is likely that other intracellular messengers are coupled to CAR1 expression. We have previously identified $\mathrm{IP}_{3}$ and diacylglycerol, the products of phosphotidylinositol bisphosphate cleavage by phospholipase $\mathrm{C}$, as potential activators of developmentally regulated gene expression in Dictyostelium /Ginsburg and Kimmel 1989).

As cells proceed through aggregation, a larger size form of CAR1 mRNA is expressed, and only this new size form persists through the remainder of the developmental program. The differences among these mRNAs reside in their 5 '-untranslated regions. The developmentally regulated changes in size of the CAR 1 RNAs could result from alternative transcriptional initiation sites or alternative splicing. The Dictyostelium phosphodiesterase gene encodes multiple sized mRNAs, and recent evidence indicates the presence of both stage-specific initiation and splice sites (Podgorski et al. 1989; Faure et al. 1990).

In the initial hours of development, the binding of secreted cAMP to surface receptors elicits a number of $\mathrm{G}^{-}$

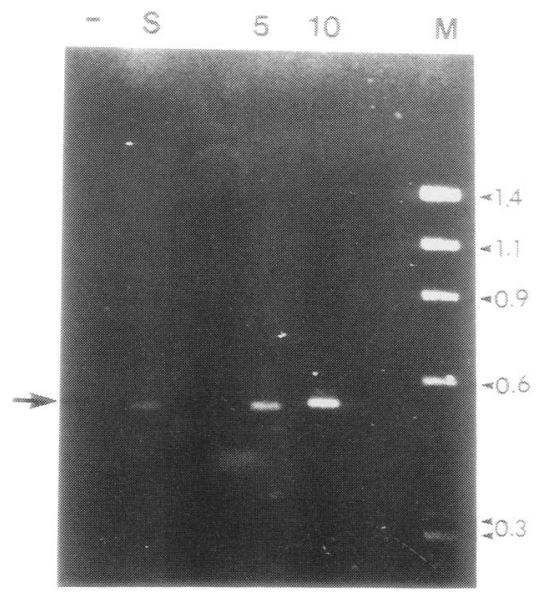

Figure 11. Mapping of the protein-coding region of CAR1 mRNA by PCR. RNAs were isolated from cells that were differentiated in the suspension culture(s) or developed on filters for 5 or $10 \mathrm{hr}$. The region of CAR 1 mRNA between nucleotides 1 (relative to the AUG) and +538 was amplified in each of these preparations by the PCR technique (see Materials and methods). These products were then analyzed by gel electrophoresis. The predominant 539 -bp band seen at all time periods is indicated by the arrow. No PCR amplification is observed if reverse transcriptase $(-)$ is not included prior to PCR. Size markers $(\mathrm{M})$ (in $\mathrm{kb}$ ) of $\phi \times 174$ replicative form DNA were digested with restriction enzyme HaeIII. 
protein-mediated responses including chemotaxis, the activation of adenylyl and guanylyl cyclases and of phospholipase $\mathrm{C}$, and the modulation of the expression of a large number of genes (for review, see Firtel et al. 1989|. Following aggregation, extracellular cAMP is involved in the determination of cell fates and pattern formation.

In early development, subtle differences in the kinetics of ${ }^{3} \mathrm{H}$-labeled cAMP binding and in elicited responses to cAMP are proposed to result from different receptor classes that interact with specific signaling pathways (Janssens and van Haastert 1987). Moreover, the duration of responses to cAMP differs between the early and later stages of development. Many cellular responses observed in early development adapt to a continous presence of cAMP, whereas cytodifferentiation and correlated changes in gene expression in later development require constant cAMP stimulation /Schaap and van Driel 1985; Gomer et al. 1986; Haribabu and Dottin 1986; Oyama and Blumberg 1986; Kimmel 1987). It has not been clear whether these various receptor forms represent the interaction of identical proteins with distinct intracellular components or whether they represent related proteins encoded by different genes. On the one hand, the pharmacological specificities of the various cellular responses are identical (Theibert et al. 1986). In contrast, certain responses appear during late developmental stages when CAR1 protein levels decline dramatically (Schaap and Spek 1984; Klein et al. 1987).

Our discovery of multiple genes that are related to CAR1 may resolve these issues. We have recently isolated genomic and cDNA clones for three genes with extensive sequence identity to CAR1 (C.L. Saxe, P.N. Devreotes, and A.R. Kimmel; R.L. Johnson, C.L. Saxe, A.R. Kimmel, and P.N. Devreotes, both in prep.; J.M. Louis, G. Ginsburg, and A.R. Kimmel, unpubl.). Each would potentially encode proteins with seven membrane-spanning domains. Preliminary findings suggest that they encode distinct cAMP receptor subtypes. Experiments are in progress to describe the precise patterns of temporal and spatial expressions of each of these genes to determine whether they encode cAMP-binding proteins, and to which effector system(s) these receptors might couple.

\section{Materials and methods}

Growth and development of cells

$D$. discoideum wild-type strain was grown on bacteria and developed on filters as described previously (Ginsburg and Kimmel 1989). Strains Ax-3, HC-33 (Coukell et al. 1983), and agip 53 (Darmon et al. 1977) were grown in HL-5 liquid medium and differentiated in shaking culture as described previously (Kimmel 1987).

\section{Isolation and hybridization of RNA and DNA}

Total and poly $(\mathrm{A})^{+}$RNA were prepared from cells as described previously (Kimmel 1987). RNA was size-separated on formaldehyde-agarose gels, transferred to GeneScreen (New England Nuclear), and hybridized to radiolabeled probes (Kimmel 1987).
Genomic DNA was isolated as described (Kimmel and Firtel 1985). DNA was separated by size on agarose gels, transferred to GeneScreen Plus or nitrocellulose, and hybridized to radiolabeled probes. Radiolabeling of probes was performed by the random primer method using $\left[\alpha^{-32} \mathrm{P}\right] \mathrm{dCTP}$. High-stringency and reduced-stringency buffer conditions were identical, $50 \%$ formamide/0.8 $\mathrm{M} \mathrm{Na}^{+}$. High-stringency hybridizations were performed at $37^{\circ} \mathrm{C}$, and reduced-stringency hybridizations were performed at $22^{\circ} \mathrm{C}$.

\section{DNA sequencing}

Sequencing was done by the dideoxy chain-termination method (Sanger et al. 1977) as applied to double-stranded DNA.

\section{RNase $H$ digestion}

RNAs were hybridized with CAR1-specific oligonucleotides (see Fig. 9). Hybrid molecules were cleaved with RNase $\mathrm{H}$ (2000 $\mathrm{U} / \mathrm{ml}$ ) in $50 \mathrm{~mm}$ Tris (pH 8.0), $10 \mathrm{~mm} \mathrm{MgCl}, 150 \mathrm{~mm} \mathrm{NaCl}$, and $0.4 \mathrm{~mm} \mathrm{DTT}$ at $37^{\circ} \mathrm{C}$, and products were identified by RNA blot hybridization (Berger 1987).

\section{Sequence amplification by $P C R$}

Poly $(\mathrm{A})^{+}$RNA was reverse-transcribed using AMV reverse transcriptase (Promega) and a 3 '-oligonucleotide primer that was specific for CAR1 (see Fig. 11). The CAR1 cDNA products were amplified by PCR using Taq DNA polymerase (Cetus) and fresh $3^{\prime}$ - and $5^{\prime}$-specific primers (Saiki et al. 1985). Total genomic $D$. discoideum DNA and cloned genomic CAR1 fragments were also amplified using CAR1-specific primers. The 5' primer was located within the $5^{\prime}$-untranslated region of the mRNA, and the various $3^{\prime}$ primers were located within intron I or the protein-coding region (see Fig. 3). All of the PCRs were cycled 25 times for $1 \mathrm{~min}$ at $94^{\circ} \mathrm{C}, 2 \mathrm{~min}$ at $37^{\circ} \mathrm{C}$, and $5 \mathrm{~min}$ at $72^{\circ} \mathrm{C}$ using a Perkin-Elmer Cetus thermal cycler.

\section{Acknowledgments}

We thank Dr. R. Crouch for his generous donation of RNase H. We also appreciate the helpful comments and discussion of Drs. C. Londos, T. Sargent, and R. Simpson.

The publication costs of this article were defrayed in part by payment of page charges. This article must therefore be hereby marked "advertisement" in accordance with 18 USC section 1734 solely to indicate this fact.

\section{References}

Berger, S.L. 1987. Direct mapping of rare messenger RNAs by means of oligomer-directed ribonuclease $\mathrm{H}$ cleavage. Anal. Biochem. 161: 272-279.

Coukell, M.B., S. Lappano, and A.M. Cameron. 1983. Isolation and characterization of cAMP unresponsive (frigid) aggregation deficient mutants of Dictyostelium discoideum. Dev. Genet. 3: 283-297.

Darmon, M., P. Barrand, P. Brachet, C. Klein, and L. Pereira Da Silva. 1977. Phenotypic suppression of morphogenetic mutants of Dictyostelium discoideum. Dev. Biol. 58: 174-184.

Devreotes, P.N. 1982. Chemotaxis. In The development of Dictyostelium discoideum (ed. W.F. Loomis), pp. 117-168. Academic Press, New York.

-1989. Dictyostelium discoideum: A model system for cell-cell interactions in development. Science 245: 10541058. 
Dinauer, M.C., T.L. Steck, and P.N. Devreotes. 1980. Cyclic 3', 5'-AMP relay in Dictyostelium discoideum. Adaptation of the cAMP signaling response during cAMP stimulation. $/$. Biol. Chem. 86: 554-561.

Dohlman, H.G., M.G. Caron, and R.J. Lefkowitz. 1987. A family of receptors coupled to guanine nucleotide regulatory proteins. Biochemistry 26: 2657-2664.

Faure, M., J. Franke, A.L. Hall, G.J. Podgorski, and R.H. Kessin. 1990. The cyclic nucleotide phosphodiesterase gene of Dictyostelium discoideum contains three promoters specific for growth, aggregation and late development. Mol. Cell. Biol. 10: 1921-1930.

Firtel, R.A., P.J.M. van Haastert, A.R. Kimmel, and P.N. Devreotes. 1989. G protein linked signal transduction pathways in development: Dictyostelium as an experimental system. Cell 58: 235-239.

Ginsburg, G. and A.R. Kimmel. 1989. Inositol trisphosphate and diacylglycerol can differentially modulate gene expression in Dictyostelium. Proc. Natl. Acad. Sci. 86:93329336.

Gomer, R.H., D. Armstrong, B.H. Leichtling, and R.A. Firtel. 1986. cAMP induction of prespore and prestalk gene expression in Dictyostelium is mediated by the cell surface cAMP receptor. Proc. Natl. Acad. Sci. 83: 8624-8628.

Haribabu, B. and R.P. Dottin. 1986. Pharmacological characterization of cyclic AMP receptors mediating gene regulation in Dictyostelium discoideum. Mol. Cell. Biol. 6: 24022408 .

Janssens, P.M.W. and P.J.M. Van Haastert. 1987. Molecular mechanisms of transmembrane signal transduction in Dictyostelium discoideum. Microbiol. Rev. 51: 396-418.

Juliani, M.H. and C. Klein. 1978. A biochemical study of the effects of cAMP on aggregateless mutants of Dictyostelium discoideum. Dev. Biol. 62: 162-172.

Kimmel, A.R. 1987. Different molecular mechanisms for cAMP regulation of gene expression during Dictyostelium development. Dev. Biol. 122: 163-171.

Kimmel, A.R. and R.A. Firtel. 1980. Intervening sequences in a Dictyostelium gene that encodes a low abundance class mRNA. Nucleic Acids Res. 8: 5599-5610.

- 1985. Sequence organization and developmental expression of an interspersed, repetitive element and associated single-copy DNA sequences in Dictyostelium discoideum. Mol. Cell. Biol. 5: 2123-2130.

Kimmel, A.R. and B. Carlisle. 1986. A gene expressed in undifferentiated vegetative Dictyostelium is repressed by developmental pulses of cAMP and reinduced during dedifferentiation. Proc. Natl. Acad. Sci. 83: 2506-2510.

Kimmel, A.R. and C.L. Saxe. 1986. cAMP-controlled gene expression in Dictyostelium developmental mutants exhibiting abnormal patterns of developmental cAMP metabolism. Dev. Biol. 117: 209-214.

Klein, P.S., R. Vaughan, J. Borleis, and P.N. Devreotes. 1987. The surface cyclic AMP receptor in Dictyostelium. Levels of ligand-induced phosphorylation, solubilization, identification of primary transcript, and developmental regulation of expression. J. Biol. Chem. 262: 358-364.

Klein, P.S., T.J. Sun, C.L. Saxe, A.R. Kimmel, R.L. Johnson, and P.N. Devreotes. 1988. A chemoattractant receptor controls development in Dictyostelium discoideum. Science 241: $1467-1472$.

Kumagai, A., M. Pupillo, R. Gunderson, R. Miake-Lye, P.N. Devreotes, and R.A. Firtel. 1989. Regulation and function of G $\alpha$ protein subunits in Dictyostelium. Cell 57: 265-275.

Loomis, W.F. 1982. The Development of Dictyostelium discoideum. Academic Press, New York.
Mann, S. and R.A. Firtel. 1987. Cyclic AMP regulation of early gene expression in Dictyostelium discoideum: Mediation via the cell surface cyclic AMP receptor. Mol. Cell. Biol. 7: 458-469.

Oyama, M. and D.D. Blumberg. 1986. Interaction of cAMP with the cell-surface receptor induces cell-type-specific mRNA accumulation in Dictyostelium discoideum. Proc. Natl. Acad. Sci. 83: 4819-4823.

Podgorski, G.J., J. Franke, M. Faure, and R.H. Kessin. 1989. The cyclic nucleotide phosphodiesterase gene of Dictyostelium discoideum utilizes alternate promoters and splicing for the synthesis of multiple mRNAs. Mol. Cell. Biol. 9: 39383950.

Saiki, R.K., S. Scharf, F. Faloona, K.B. Mullis, G.T. Horn, H.A. Erlich, and N. Arnheim. 1985. Enzymatic amplification of $\beta$-globin genomic sequences and restriction site analysis for diagnosis of sickle cell anemia. Science 230: 1350-1354.

Sanger, F., S. Nicklen, and A.R. Coulson. 1977. DNA sequencing with chain-terminating inhibitors. Proc. Natl. Acad. Sci. 74: 5463-5467.

Schaap, P. and W. Spek. 1984. Cyclic AMP binding to the cell surface during development of Dictyostelium discoideum. Differentiation 27: 83-87.

Schaap, P. and R. van Driel. 1985. The induction of post-aggregative differentiation in Dictyostelium discoideum. Exp. Cell Res. 159: 388-398.

Snaar-Jagalska, B.E., F. Kesbeke, and P.J.M. van Haastert. 1988. G-proteins in the signal-transduction pathways of Dictyostelium discoideum. Dev. Genet. 9: 215-226.

Theibert, A., M. Palmisano, B. Jastorff, and P. Devreotes. 1986. The specificity of the cAMP receptor mediating activation of adenylate cyclase in Dictyostelium discoideum. Dev. Biol. 114: 529-533.

Van Haastert, P.J.M. 1987. Down-regulation of cell surface cyclic AMP receptors and desensitization of cyclic AMP-stimulated adenylate cyclase by cyclic AMP in Dictyostelium discoideum. J. Biol. Chem. 262: 7700-7704.

Wahl, G.M., S.L. Berger, and A.R. Kimmel. 1987. Molecular hybridization of immobilized nucleic acids: Theoretical concepts and practical considerations. Methods Enzymol. 152: $399-407$.

Wang, M., R. Van Driel, and P. Schaap. 1988. Cyclic AMP phosphodiesterase induces dedifferentiation of prespore cells in Dictyostelium discoideum slugs: Evidence that cyclic AMP is the morphogenetic signal for prespore differentiation. Development 103: 611-618.

Wurster, B. and J. Bumann. 1981. Cell differentiation in the absence of intracellular cyclic AMP pulses in Dictyostelium discoideum. Dev. Biol. 85: 262-265. 


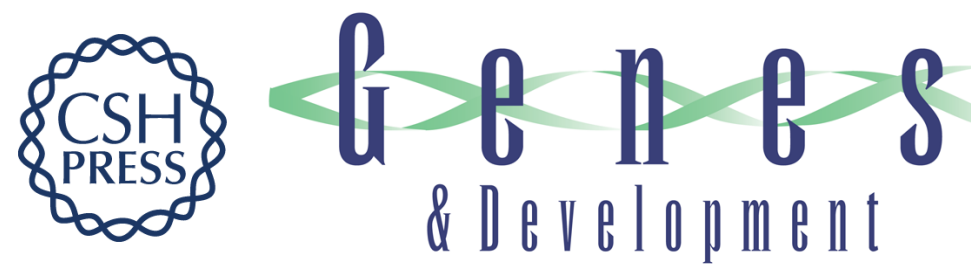

\section{Expression of a cAMP receptor gene of Dictyostelium and evidence for a multigene family.}

C L Saxe, R L Johnson, P N Devreotes, et al.

Genes Dev. 1991, 5:

Access the most recent version at doi:10.1101/gad.5.1.1

References This article cites 34 articles, 17 of which can be accessed free at:

http://genesdev.cshlp.org/content/5/1/1.full.html\#ref-list-1

License

Email Alerting

Service

Receive free email alerts when new articles cite this article - sign up in the box at the top right corner of the article or click here.

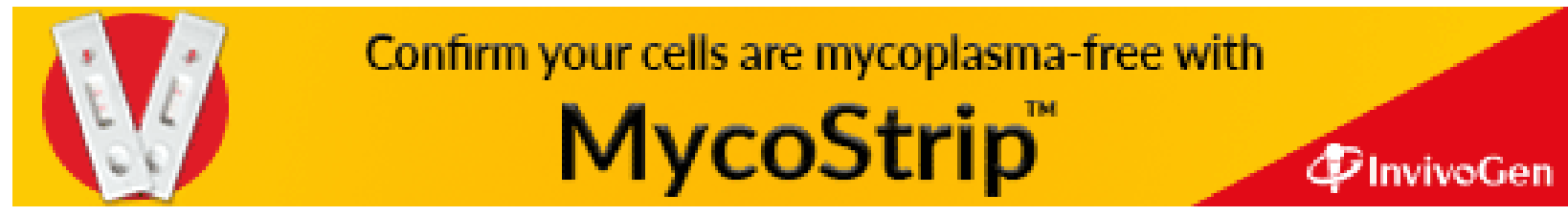

